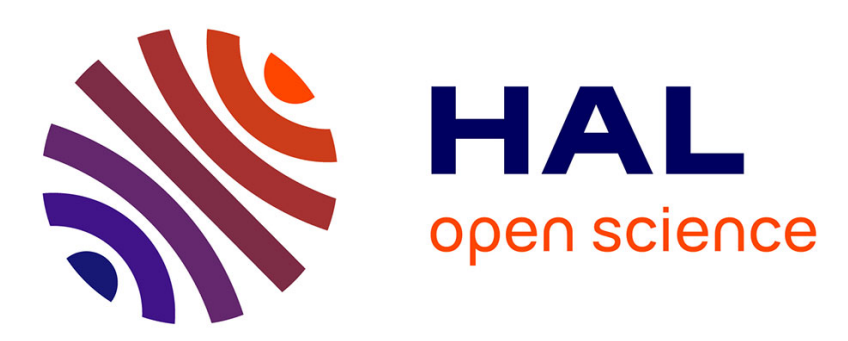

\title{
Thermal instability of silicon-on-insulator thin films measured by low-energy electron microscopy
}

\author{
E. Bussmann, F. Cheynis, Frédéric Leroy, P. Muller
}

\section{To cite this version:}

E. Bussmann, F. Cheynis, Frédéric Leroy, P. Muller. Thermal instability of silicon-on-insulator thin films measured by low-energy electron microscopy. IOP Conference Series: Materials Science and Engineering, 2010, 12, pp.012016. 10.1088/1757-899x/12/1/012016 . hal-01967071

\section{HAL Id: hal-01967071 \\ https://hal.science/hal-01967071}

Submitted on 4 Jan 2019

HAL is a multi-disciplinary open access archive for the deposit and dissemination of scientific research documents, whether they are published or not. The documents may come from teaching and research institutions in France or abroad, or from public or private research centers.
L'archive ouverte pluridisciplinaire HAL, est destinée au dépôt et à la diffusion de documents scientifiques de niveau recherche, publiés ou non, émanant des établissements d'enseignement et de recherche français ou étrangers, des laboratoires publics ou privés. 


\title{
Thermal instability of silicon-on-insulator thin films measured by low-energy electron microscopy
}

\author{
E. Bussmann, F. Cheynis, F. Leroy and P. Müller \\ Centre Interdisciplinaire de Nanoscience de Marseille, CNRS UPR 3118 , Aix-Marseille \\ Université, Case 913 Campus de Luminy, 13288 Marseille Cedex 9, France \\ E-mail: muller@cinam.univ-mrs.fr
}

\begin{abstract}
Using low-energy electron microscopy (LEEM), we investigate the ultrahigh vacuum annealing of silicon-on-insulator (SOI) samples capped by a chemically-prepared oxide layer. Consistent with previous reports: (1) for $T>750^{\circ} \mathrm{C}$, the capping-oxide decomposes by void nucleation and growth, then (2) for $T>850^{\circ} \mathrm{C}$, the Si thin-film dewets from the $\mathrm{SiO}_{2}$ substrate. Here, we show that the morphological evolution of the surface during the dewetting process is dependent on the preparation of the SOI surface. Two dewetting pathways are evident in recent literature, we find that one evolution is characteristic of clean $\mathrm{Si}(100)-2 \times 1$ surfaces, while the other is correlated with surface contamination.
\end{abstract}

Silicon thin-films, capped by ultra-thin oxide layers, are the basic building blocks of microelectronics. Microelectronic device fabrication requires thermal annealing steps, which may induce drastic morphological changes in these building blocks. Here, we explore the annealing behavior of oxide-capped silicon-on-insulator (SOI) films. During annealing at $T>750^{\circ} \mathrm{C}$, the oxide capping layer decomposes (Fig. 1(a)) by void nucleation and growth. Then at $T>850^{\circ} \mathrm{C}$, the Si thin film spontaneously dewets (Fig. 1(b)), forming an assembly of three dimensional Si nanocrystals. Previous works $[1,2,3,4,5]$ have explored the thermal decomposition of ultrathin Si-oxide, and the subsequent dewetting of the Si (SOI) layer [6, 7]. Here, we report two results which, to our knowledge, have not been reported previously. During thermal decomposition of the capping oxide layer, the radii of the initial isolated voids obeys a $r \propto t^{1 / 3}$ law. This exponent suggests that void growth is governed by diffusion of the decomposition product ( $\mathrm{SiO}$ molecules) on the oxide outside the voids. The decomposition of the oxide exposes a $2 \times 1$ reconstructed surface, characteristic of clean $\mathrm{Si}(100)$, ideal for studying the mechanisms of the SOI dewetting process. The dewetting proceeds by the opening of square, crystallographically oriented holes, followed by a finger instability that leads to the formation of self-organized, 
crystallographically-oriented Si nanocrystals. By contrast, for surfaces prepared only by ex-situ hydrogen termination in hydrofluoric acid, dewetting proceeds by circular holeopening yielding disordered nanocrystals. Using low-energy electron diffraction (LEED), we correlate the latter behavior with residual surface contamination.

The samples under investigation are bonded-SOI(001) (SmartCut ${ }^{\circledR}, C E A$-Leti, France) with a Si thickness of $22 \pm 2 \mathrm{~nm}$ on a 147-nm-thick oxide layer. The samples are chemically cleaned ex-situ by repeated cycles of chemical oxidation/deoxidation, followed by a final oxidation in $\mathrm{H}_{2} \mathrm{O}_{2}: \mathrm{H}_{2} \mathrm{O}: \mathrm{HCl}$ solution yielding a 1-2 nm-thick oxide capping layer. Then the samples are introduced in UHV and degassed for a few hours at $600^{\circ} \mathrm{C}$. The sample deoxidation and dewetting are studied in real-time by low-energy electron microscopy (LEEM III, Elmitec GmbH). The pressure inside the LEEM chamber is below $10^{-9}$ Torr during the experiments. The samples are heated by electron bombardment. The sample temperature is measured by a thermocouple at the back-side of the sample.

(a)

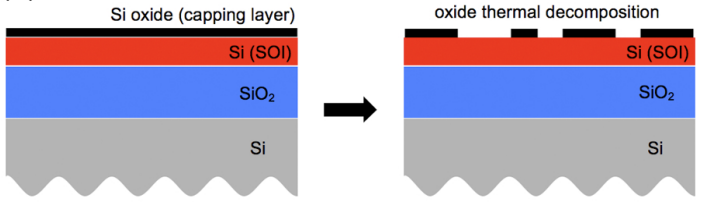

(b)

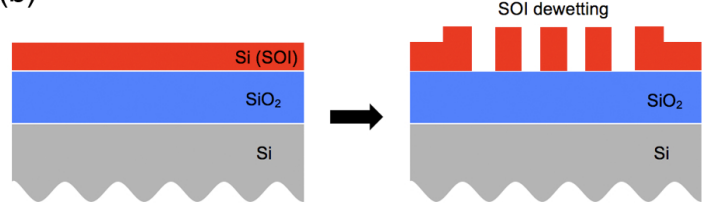

Figure 1. Schematic representation of the oxide-capped silicon-on-insulator samples during annealing. (a) Thermal decomposition of the capping-oxide by void growth. (b) Subsequent dewetting of the Si thin-film

Figure 2(a) shows LEEM images taken during thermal decomposition (at $790^{\circ} \mathrm{C}$ ) of the ultra-thin oxide capping layer. The decomposition proceeds by void nucleation and growth as already reported $[1,2,3,5]$.

From previous reports [1, 2, 3, 5], the void-opening proceeds by: (i) Si adatom creation inside the void, (ii) $\mathrm{Si}$ adatom diffusion towards the void periphery, (iii) $\mathrm{Si}+\mathrm{SiO}_{2} \rightarrow 2$ $\mathrm{SiO}$ chemical reaction at the periphery, (iv) $\mathrm{SiO}$ desorption at the void edge. A simple phenomenological analysis shows that this scenario naturally leads to two limiting laws governing void growth: (1) if the rate-limiting step is the reaction at the periphery, the time evolution of the void area $A$ can be written $d A / d t \propto \sqrt{A}$ yielding a void-radius evolution $r(t) \propto C^{t e} t$. (2) On the other hand, if the rate-limiting step is monomer creation, $d A / d t \propto A$ yielding $r(t) \propto e^{C^{t e} t}$. In our experiments, the radii of voids evolve obeying $r(t) \propto t^{1 / 3}$ (see Fig. $2(\mathrm{~b})$ ). These laws can be obtained as limiting cases of a more general model taking into account the diffusion of $\mathrm{Si}$ and $\mathrm{SiO}$ at the surface [8]. The model predicts $r(t) \propto t^{1 / 3}$ (following the approach in $[9,10,11]$ ), if void-growth is limited by SiO diffusion on the oxide outside the voids [12].

When the voids have coalesced, thermal decomposition of the oxide is complete and the clean $2 \times 1$-reconstructed $\operatorname{Si}(100)$ surface is exposed. By LEED measurements, we find that the surface has the $2 \times 1$ dimer reconstruction, characteristic of clean $\mathrm{Si}(100)$ (see Fig. 3(a)). 
(a)
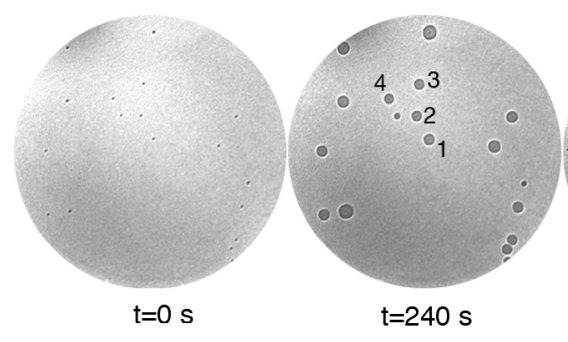

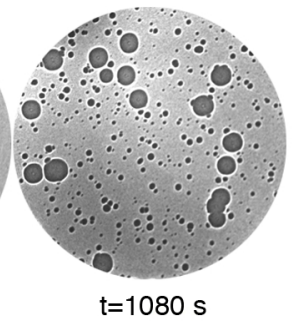

(b)

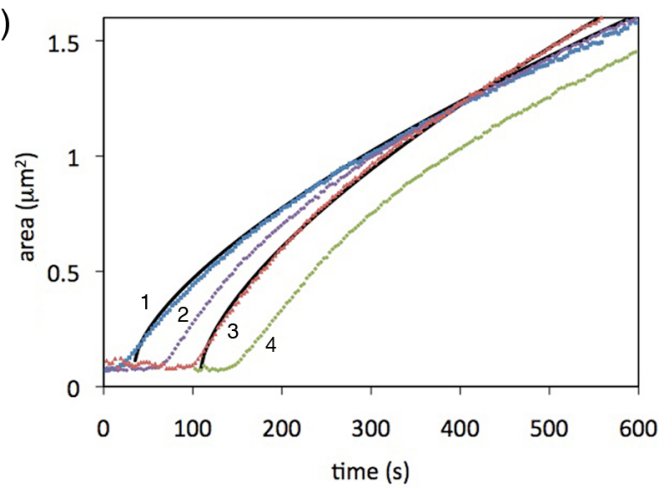

Figure 2. Thermal decomposition of the capping oxide. (a) Sequence of LEEM images (Field of view $25 \mu \mathrm{m}, E=0.4 \mathrm{eV}$ ) showing void opening at $790^{\circ} \mathrm{C}$. (b) Voids area versus time for holes 1 to 4 (dots). The best fits (continuous lines) are obtained for $A(t) \propto t^{2 / 3}$

A subsequent anneal $\left(T>850^{\circ} \mathrm{C}\right)$, leads to the dewetting phenomenon, in which the $\mathrm{Si}$ film breaks down into nanocrystals. Fig. 3 shows the dewetting evolution as function of time for two different surface preparations. Fig. 3(a) shows an image sequence of dewetting of a sample prepared by thermal deoxidation (as described). Fig. 3(b) shows an image sequence of dewetting of a sample prepared only by an ex-situ dip into dilute HF acid (5\% by volume), yielding a H-terminated surface.

For the surface prepared by thermal deoxidation, the dewetting holes are square-shaped, with edges oriented along [110] directions of the SOI film. Hole-opening progresses via a fingering instability (see Fig. 3 (a) $t=1080 \mathrm{~s}$ ). The fingers breakdown into rows of ordered nano-size Si crystals aligned along the [130], [150] or [100] directions (see Fig. 3 (a) at $t=2040 \mathrm{~s}$ ). For the HF-dipped sample (see Fig. 3 (b)), (i) the dewetting holes are roughly circular, (ii) there is no fingering instability, (iii) the nanocrystals are disordered.

For the HF-prepared sample, we expect to see a $2 \times 1$-reconstruction (during annealing $\mathrm{H}$ should desorb leaving a clean surface). Instead, we observe a diffuse $4 \times 4$ LEED pattern (Fig. 3 (b)). This is likely due to residual carbon contamination [13]. A difference in surface morphology is also apparent in LEEM darkfield imaging, which yields bright-dark contrast between the $2 \times 1$ and $1 \times 2$-oriented domains of the $\operatorname{Si}(100)$ surface. The bright-dark speckling in the images in Fig. 3 (a) is not contamination, but individual clean terraces, several-hundred-nanometers-wide, with $1 \times 2$ (dark) and $2 \times 1$ (bright) reconstructions. These large clean terraces are not apparent on HF-prepared surfaces Fig. 3 (b).

The comparison of sequences of images of Fig. 3(a) and (b) clearly illustrates that all steps of the complex mechanism of dewetting are affected by the surface preparation. We conclude that it is crucial to control the cleanness of the Si surface when studying dewetting mechanisms. Indeed, some of the dewetted silicon thin films reported in the recent literature look like Fig. 3(b) $[6,14,15]$ and thus likely correspond to poorly prepared (contaminated) surfaces for which experimental results must be handled with care. 

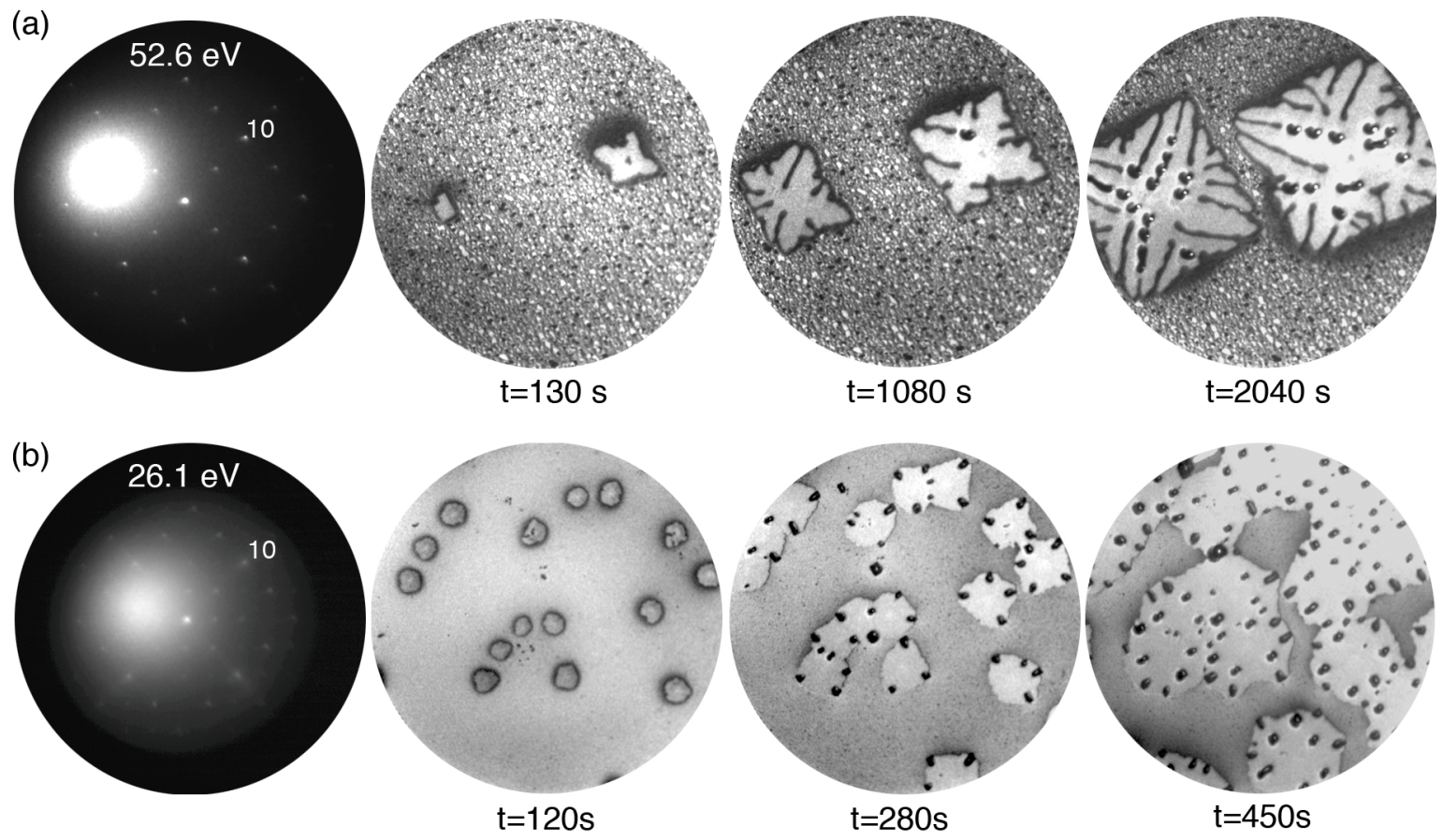

Figure 3. LEED/LEEM of dewetting of $22 \mathrm{~nm}$-thick SOI films prepared by (a) oxide desorption in UHV prior to dewetting $\left(T=875^{\circ} \mathrm{C}\right.$, FOV $\left.25 \mu \mathrm{m}, E=7.8 \mathrm{eV}\right)$ (b) a dip in hydrofluoric acid, no chemical oxidation $\left(T=1000^{\circ} \mathrm{C}\right.$, FOV $\left.25 \mu \mathrm{m}, E=3.8 \mathrm{eV}\right)$.

Acknowledgements We thank T. Passanante for the sample preparation. This work is supported by ANR PNano Grant DEFIS (ANR 08-Nano-036).

[1] Hibino H, Uetmatsu M and Watanabe Y 2006 J. Appl. Phys. 100, 113519

[2] Liehr M, Lewis J and Rubloff G 1987 J. Vac. Sci. Technol. A 51559

[3] Miyata N, Watanabe H and Ichikawa M 2000 Phys. Rev. Lett. 841043

[4] Johnson K and Engel T 1992 Phys. Rev. Lett. 69339

[5] Ogawa S and Takakuwa Y 2006 Japan J. of Appl. Phys. 457063

[6] Danielson D, Sparacin D, Michel J and Kimerling L C 2006 J. Appl. Phys. 100083507

[7] Sutter P, Ernst W, Choi Y and Sutter E 2006 Appl. Phys. Lett. 88141924

[8] Burton W, Cabrera N and Frank F 1951 Philos. Trans. R. Soc. London Ser. A 243299

[9] Pang A, Man K, Altman M, Stasevich T, Szalma F and Einstein T L 2008 Phys. Rev. B 77115424

[10] McLean J, Krishnamachari B, Peale R, Chason E, Sethna J and Cooper B 1997 Phys. Rev. B 551811

[11] Krishnamachari B, McLean J, Cooper B and Sethna J 1996 Phys. Rev. B 548899

[12] P. Müller et al., in preparation.

[13] Butz R and Luth H 1998 Surf. Sci. 41161

[14] Legrand B, Agache V, Melin T, Nys J P, Senez V and Stievenard D 2002 J. Appl. Phys. 91106

[15] Capellini G, Giasca G, de Seta M, Notargiamoco A, Evangestelli F and Nardone M 2009 J. Appl. Phys. 105093525 